\title{
SISTEMA DE INFORMAÇÃO DE CUSTOS DO GOVERNO FEDERAL (SIC): UMA NOVA ABORDAGEM PARA A GESTÃO PÚBLICA
}

\author{
FEDERAL GOVERNMENT COSTS INFORMATION SYSTEM (CIS): A NEW \\ APPROACH TOWARD PUBLIC MANAGEMENT
}

\section{SISTEMA DE INFORMACIÓN DE COSTOS DEL GOBIERNO FEDERAL (SIC): UN NUEVO ABORDAJE PARA LA GESTIÓN PÚBLICA}

\section{VICTOR BRANCO DE HOLANDA}

Contador, Economista, Doutor em Contabilidade e Controladoria pela Faculdade de Economia Administração e Contabilidade da Universidade do Estado de São Paulo (FEA/USP).

Professor da UFRN, Consultor Residente do FMI no Brasil para o tema Custos, como suporte a avaliação de resultado e desempenho no setor publico, atuando no projeto de implantação de custos do Estado de São Paulo. Membro do Grupo de Trabalho do ConseIho Federal de Contabilidade para o processo de convergência das Normas Brasileiras de Contabilidade do Setor Público aos padrões Internacionais. Foi Diretor de Gestão Estratégica do Ministério da Fazenda de 2007 a 2010 atuando, principalmente, no programa de melhoria da qualidade do gasto no setor público e no projeto de implantação do sistema de custos do Governo federal. Entre 2004 e 2007, foi diretor dos programas de melhoria da Gestão com Cooperação Internacional no Ministério do Planejamento.

victorbholanda@gmail.com

Esta resenha tem por finalidade apresentar os principais tópicos do processo de concepção, desenvolvimento e implantação do Sistema de Informação de Custos do Governo Federal (SIC). A introdução traz o que chamamos de "uma nova abordagem de gestão pública"; na sequência, o sistema de informação de custos do Governo federal é rapidamente explorado, contemplando ainda a obrigatoriedade legal; a estratégia de desenvolvimento e implantação; os avanços alcançados com a primeira versão do SIC; e, finalmente, alguns desafios em sua perspectiva de futuro. 
1) Uma nova abordagem de gestão pública: a priorização da mensuração de custos no Governo federal brasileiro integra uma das etapas essenciais para a transformação de paradigmas atualmente existentes sobre o papel e importância do setor público como agente propulsor de geração de eficiência no uso de recursos públicos. As informações de custos devem ser a base para a formulação da proposta orçamentária, sendo o orçamento o fio condutor que permite executar as despesas e prestar os serviços públicos planejados. Os administradores do setor público necessitam de um conjunto de informações gerenciais para cumprirem com eficiência as políticas públicas. O sistema de informação de custos deve ser capaz de auxiliar as decisões, tais como comprar ou alugar, produzir internamente ou terceirizar determinado serviço ou atividade, e, ainda, permitir comparações entre os custos de atividades ou serviços iguais produzidos por entidades públicas diferentes. Um dos principais objetivos do SIC é conhecer e estimular a melhoria do desempenho dessas entidades.

Do ponto de vista histórico, a partir da Revolução Industrial, no século XVIII, a Contabilidade de Custos começou a ganhar importância. Anteriormente, as informações geradas por meio da Contabilidade Financeira eram suficientes para as empresas comerciais, predominantes durante a Era Mercantilista. Foi somente com o desenvolvimento da Contabilidade Gerencial que o potencial da informação de custo começou a ser aproveitado para fins de gerenciamento das organizações. Essa mudança no perfil da Contabilidade de Custos possibilitou também o seu uso em outros campos, além da Contabilidade Industrial, passando, por exemplo, pela "indústria" financeira até chegar mais recentemente à Contabilidade Pública.

2) A obrigatoriedade legal: a Lei $n .{ }^{\circ} 4.320$, promulgada em 17 de março de 1964 , ao tratar da apuração de custos nos arts. 85 e 99, restringia o seu uso à área industrial da administração pública. Posteriormente, o Decreto-Lei n. ${ }^{\circ}$ 200, de 25 de fevereiro de 1967, ao buscar a modernização da administração pública, estimulou a criação de uma administração gerencial no setor público. Com o Decreto, as informações de custos passaram a ter uma finalidade gerencial. Tais disposições, no entanto, não foram suficientes para que a Contabilidade Pública começasse a produzir informações que permitissem a apuração dos custos dos programas do Governo, bem como dos serviços gerados.

O Decreto Presidencial n. ${ }^{\circ}$ 93.872/1986 detalhou a forma pela qual a Contabilidade deveria apurar os custos dos serviços, bem como determinou punição para as unidades que não disponibilizassem as informações pertinentes para permitir essa evidenciação. Posteriormente, a Lei de Responsabilidade Fiscal trouxe novo dispositivo para a administração pública sobre o tema de custos, em seu Art. 50, § $3^{\circ}$ : "A Administração Pública manterá sistema de custos que permita a avaliação e o acompanhamento da gestão orçamentária, financeira e patrimonial". A Lei n. ${ }^{\circ} 10.180$, de 6 de fevereiro de 2001, organizou o Sistema de Contabilidade Federal do Poder Executivo, concedendo à Secretaria do Tesouro Nacional a competência para tratar de custos na administração pública federal. 
Considerando que a obrigatoriedade legal de se produzir e utilizar informação de custos no setor público já estava contemplada nos arts. 85 e 89 da Lei n. ${ }^{\circ} 4.320$, de 17 de março de 1964, e sendo esta mesma obrigatoriedade legal explicitamente reforçada no Art. 50 , $\S 3^{\circ}$ da Lei de Responsabilidade Fiscal de 2000, os questionamentos decorrentes são: por que a administração pública federal não havia ainda construído e disponibilizado o seu sistema de informação de custos? Por que, passados exatos 46 anos após a primeira Lei (a de $\left.n .{ }^{\circ} 4.320\right)$ e 10 anos após o reforço da LFR, ambas com promessa de punição aos gestores pelo seu descumprimento, só em março de 2010 o sistema de informação de custos do Governo federal foi finalmente homologado em sua primeira versão?

É preciso ressaltar que a utilização sistemática da informação de custos no setor público não é uma tarefa simples, porque ela requer vários requisitos, principalmente os de integração sistêmica, pois, no Estado, dadas as suas dimensões, as funções de planejamento, orçamento, gestão, finanças e contabilidade estão distribuídas em ministérios (e secretarias para os níveis estadual e municipal), que, na maioria das vezes, têm dificuldades em compartilhar dados e informações, o que acaba dificultando a processo de implantação de sistema de custos.

O Sistema de Informação de Custos do Governo Federal (SIC), valendo-se de tecnologia de datawherehouse, utiliza dados dos sistemas estruturantes de Governo como base para a geração de informações, principalmente os capturados pelos sistemas de informação contábeis e financeiros. O diferencial do SIC está na sua capacidade de integrar diversos sistemas em uma única base.

O Sistema de Informação de Custos do Governo Federal operacionaliza diversas regras do nosso ordenamento jurídico, anos depois de editadas; avança na melhoria da qualidade do gasto ao propiciar a efetiva mensuração do desempenho governamental. Nesse sentido, sua relevância para o interesse público pode ser entendida mediante o seu impacto sobre a gestão pública. A partir da mensuração de custos, tanto a função planejamento como a "orçamento" podem melhorar, assim como a avaliação de políticas públicas e programas custeados por recursos públicos.

3) Estratégia de desenvolvimento e implantação do SIC: a estratégia de desenvolvimento e implantação do SIC foi decorrente da abordagem por macroprocesso aplicado, em específico, ao macroprocesso orçamentário-financeiro. Os esforços para que se chegasse à primeira versão do sistema de custos do Governo federal foram muitos. Podese destacar o trabalho da Comissão Interministerial em meados de 2005, cujo objetivo era "elaborar estudos e propor diretrizes, métodos e procedimentos para subsidiar a implantação de Sistema de Custos na Administração Pública Federal". Tal comissão foi resposta organizacional ao Acórdão n. 1.078/2004 do Tribunal de Contas da União, que determinou que fossem adotadas "providências para que a administração pública federal possa dispor com maior brevidade possível de sistema de custos, que permitam, entre outros, a ava- 
liação e o acompanhamento da gestão orçamentária e financeira de responsáveis, ante o disposto na Lei de Responsabilidade Fiscal e na LDO para 2004". Em continuidade aos trabalhos da Comissão Interministerial, foi instituída ao final de 2008 a Câmara Técnica de Qualidade do Gasto (CTQG), no âmbito do Comitê Técnico de Orçamento conduzido pela Secretaria de Orçamento Federal, do Ministério de Planejamento, Orçamento e Gestão.

Não obstante o esforço anterior, foi no início de 2009 que se formou o grupo técnico na Secretaria do Tesouro Nacional do Ministério da Fazenda com o intuito de produzir versão inicial do Sistema de Informação de Custos do Governo Federal em parceria com o Serpro. O referido grupo passa a interagir fortemente com todo o trabalho do macroprocesso orçamentário e financeiro que já estava estabelecido, fundindo-se num grupo de trabaIho maior (interministerial) e envolvendo também o Ministério do Planejamento.

Para a operacionalização do projeto, foi necessário coordenar diversos atores: ministérios e entidades governamentais, comunidade acadêmica nacional e internacional, órgãos de controle externo e governos subnacionais, entre outros. Mediante apoio da Secretaria Executiva do Ministério da Fazenda como sponsor, foi possível articular com esses diversos atores gradativamente.

Buscou-se, inicialmente, a participação e a cooperação da Secretaria de Orçamento Federal (SOF/MP), da Secretaria de Planejamento e Investimentos Estratégicos (SPI/MP) e da Secretaria de Recursos Humanos (SRH/MP), órgãos gestores, respectivamente, do Sidor, Sigplan e Siape. Em seguida, a Secretaria de Gestão (Seges/MP) e a Secretaria de Logística e Tecnologia da Informação (SLTI/MP) foram incorporadas ao processo de trabalho. Paralelamente a esta ação, foi realizada uma série de seminários "técnicos conceituais" com o envolvimento da comunidade acadêmica: inicialmente, FGV, USP, UERJ, UFRN e UFPE e, em seguida, este universo foi se expandido para várias outras universidades e entidades do terceiro setor, como o Instituto Social IRIS, até culminar com a edição do "I Congresso de Informação de Custos e Qualidade do Gasto no Setor Público". Complementarmente às ações anteriormente apontadas, foram ainda realizadas visitas técnicas para conhecer os sistemas de custos do Inmetro, do Banco Central e do Município do Rio de Janeiro.

Na fase de reforço do diagnóstico e definição das diretrizes gerais do modelo, foi elaborado e aplicado questionário aos servidores federais (1.630 questionários respondidos). Com a análise das informações, foram ratificadas as diretrizes que já estavam sendo seguidas na implantação do projeto pela Secretaria do Tesouro Nacional. Também foram realizados estudos preliminares pelo Serpro acerca dos pontos de integração nos sistemas estruturantes, com vistas à construção do Sistema de Informação de Custos e estudos acerca da metodologia de ajuste contábil, pela Coordenação Geral de Contabilidade da União.

Os seminários realizados ao longo de 2009 serviram como ponto de controle, monitoramento e divulgação do projeto. Nestes eventos, foi possível mapear, por meio do público-alvo, os potenciais impactos e usos da informação de custos nas rotinas adminis- 
trativas e na tomada de decisões. Os seminários foram transmitidos pela internet e, mesmo assim, contaram com a participação presencial média de 300 pessoas, além de permitirem capilaridade da iniciativa perante as instituições acadêmicas, unidades organizacionais e diversos ministérios da administração pública federal e governos subnacionais de um modo inédito. A cada seminário, novos parceiros foram agregados. O último, realizado em setembro de 2010, já durante a etapa de homologação do SIC, contou com palestrante internacional, presença de representantes da Controladoria Geral da União, do Tribunal de Contas da União e de governos subnacionais. Iniciativa conjunta do Ministério da Fazenda, Ministério do Planejamento, contou com a participação efetiva do setor acadêmico, da FGV e de outras universidades públicas e privadas, em sua maioria, representada pelos professores colaboradores do Instituto Social IRIS'.

Em março de 2010, a fase de homologação do sistema foi encerrada e as diretrizes de treinamento e capacitação dos usuários iniciadas. O treinamento de novos usuários foi realizado em todo o ano de 2010, em parceria com a Escola de Administração Fazendária (ESAF), utilizando-se multiplicadores treinados dos seguintes órgãos: STN, SOF, SRH, SPI, SEGES e SLTI.

4) Avanços alcançados com a primeira versão do SI: o Sistema de Informação de Custos do Governo Federal permite a efetiva mensuração de custos sob a ótica administrativa e programática, a partir dos órgãos centrais de planejamento, orçamento, contabilidade e finanças, com vistas a atender de forma uniforme a todos os órgãos e entidades da estrutura federal. Alguns avanços são marcadamente alcançados nesta primeira versão do SIC. De forma resumida, pode-se destacar o tratamento conceitual adequado e a abordagem tecnológica apropriada que permite trazer a dimensão temporal de maneira explícita com a realização de inferências multidimensionais. Com a maturidade do sistema em questão, será possível aperfeiçoar as séries históricas de análise de custos sob a ótica administrativa ou programática, estimulando o uso de ferramentas OLAP (On line Analitical Processing), que permitem acesso rápido aos dados conjugado à facilidade de acesso pelos usuários.

A escolha tecnológica para o desenvolvimento do Sistema de Custos foi a criação de uma base de dados acessada através de um datawarehouse. O datawarehouse é um repositório de dados eletrônicos, projetado de forma a facilitar a criação de relatórios e a análise dos dados. Os dados são carregados através de uma técnica denominada ETL (Extract, Transform, Load), que abrange a extração de dados dos sistemas dos quais eles se originam, a sua transformação para a adequação da informação e a efetiva carga desses dados no sistema. No caso do SIC do Governo federal, a carga dos dados é realizada mensalmente. Outra vantagem da escolha do datawarehouse é a sua capacidade de per-

1 O Instituto Social IRIS é uma associação de professores pesquisadores de diversas universidades públicas e privadas, organizada em forma de rede, cujo objetivo é a melhoria da Contabilidade, transformando-a em instrumento efetivo de controle social. Vide linhas de pesquisas em http://www.socialiris.org. 
mitir o manuseio e a gestão de grande volume de dados. Essa capacidade era um requisito essencial do projeto, visto que a base de dados armazena milhões de registros efetuados anualmente no Siafi, no Siape e no Sigplan. Para que esses dados possam ser pesquisados com rapidez, a estrutura do datawarehouse permite redundâncias e agregações de dados, o que não ocorre nos sistemas transacionais.

A estratégia de coordenação do projeto de custos também foi inédita. Não havia mapeamento, nem por parte do Serpro, dos processos e das interfaces entre os sistemas estruturantes Siafi, Siape e Sigplan, etc. Não havia também coordenação adequada nas rotinas de alteração desses sistemas. A implantação do Sistema de Informação de Custos provocou mudança significativa nessa realidade. Desde o início do projeto, todos os stakeholders envolvidos com o macroprocesso orçamentário e financeiro da União puderam refinar a comunicação organizacional e minimizar ruídos, especialmente na gestão e no aprimoramento dos sistemas, quanto à adoção de novas tecnologias.

O Sistema de Informação de Custos do Governo Federal apresenta-se como um marco histórico no desenvolvimento de sistemas gerenciais de apoio à tomada de decisão no âmbito do setor público, tanto por sua abrangência, quanto por sua metodologia de construção e implantação. O SIC já está mudando gradativamente a cultura de avaliação dos programas do Governo federal, e um exemplo disso foi a recomendação do TCU para que cada ministério escolhesse inicialmente dois programas com a finalidade de que fossem iniciadas a apuração e a análise de seus custos de forma mais sistemática, utilizando-se a metodologia e o SIC disponibilizado pela STN, consequentemente evidenciando a relação custo/benefício dos produtos e resultados dos programa e políticas públicas.

5) Desafios e Próximos Passos: o maior desafio do sistema é o de produzir informações úteis para os gestores federais, pois a vitalidade de um sistema de informação está diretamente relacionada com o uso que se faz das informações geradas. O avanço do sistema será fortalecido pela implantação de outros projetos, como o da contabilidade patrimonial, o novo Siafi e os aprimoramentos na legislação vigente. Tais iniciativas agregadas compõem a política de melhoria da qualidade do gasto público, incentivada, entre outros atores, pela Secretaria do Tesouro Nacional. A disseminação do sistema tem como base de sustentação a mudança de aspectos culturais do setor público: inicia-se pela capacitação dos usuários no uso do sistema, passa por uma gestão eficiente das informações geradas e solidifica-se na institucionalização do uso da informação de custos por parte dos órgãos centrais e apropriação desse uso pelos gestores públicos em seu processo de tomada de decisão.

O SIC, embora tenha alcançado seu objetivo inicial, passará por diversas evoluções até se tornar elemento indispensável no processo decisório da gestão pública. Com o desenvolvimento do novo Siafi, surge uma oportunidade para unificação do tratamento de custos no Governo federal, pois alguns órgãos atualmente utilizam centros de custo por meio de lançamentos contábeis em contas específicas de custos. 


\section{repc}

Um dos principais desafios ainda a ser enfrentado é a falta de uma cultura para a utilização da informação de custos. Temos consciência de que muito foi feito, muito se fez e muito ainda terá que ser feito para aperfeiçoamento, evolução e maturação de uma política de informação de custos e qualidade do gasto público. Não obstante, espera-se compromisso dos futuros governantes dos três Poderes: Executivo, Legislativo e Judiciário; a "calibragem" adequada entre o incentivo e a cobrança dos órgãos de controle; o envolvimento efetivo da academia; e a participação da sociedade civil na continuidade e no fortalecimento do SIC. 